\title{
Heritage Resources Centre
}

The Heritage Resources Centre (HCR) is based in the Faculty of Environmental Studies at the University of Waterloo, Waterloo, Ontario, Canada. The Centre is dedicated to promoting research, education, and information exchange, among those concerned with heritage in the broad, natural, and cultural, sense. The Centre's Outreach Program strives to facilitate interaction among persons and groups involved with heritage at local, regional, national, and international, levels in the public and private sectors and among interested citizens more generally. Activities at the Centre encompass geological, biological, archaeological, cultural, historical, marine, and geographical, aspects of heritage, as well as policies and institutions for heritage management and planning. The notion of heritage includes also the ideas, beliefs, and ways of life, that people value and use in the face of change.

The Outreach Program includes conferences and workshops, as well as round-tables and fora, organized for the University community and those active in local agencies and groups. Conferences are major events which last several days and normally involve a hundred or more people, many presentations, much discussion, and finally the publication of proceedings. A recent example is a conference on Ecological Integrity and the Management of Ecosystems, which was organized in conjunction with the Canadian Parks Service. The Centre is currently involved in organizing the Fourth Annual Conference of the Society for Ecological Restoration, which is to be held in Waterloo in August 1992.

The workshops are also major events which last one or two days and typically involve 30-100 participants. In many cases, the workshops are organized in association with other groups or agencies. Each workshop generally involves a keynote address followed by presentations from a panel of persons representing a variety of perspectives, small-group sessions, and a plenary to summarize findings. The workshops are of three basic types and are central to the work of the Centre.

The first type are project workshops, which are organized as part of some research or inquiry that is being conducted by the Centre. Research projects are typically motivated by an interest in working on heritage research, in a cross-disciplinary way, on the part of graduate and undergraduate students and faculty members from the University of Waterloo and elsewhere. Recent examples include workshops on resource survey for coastal-zone management along the Lake Huron shore, assessing environmental management in Canada and Europe, and examining the links between environmental assessment and heritage in Canada.
The other two types of workshops are certificate seminars and public workshops. Certificate seminars deal with issues of interest to professionals in the educational, government, and private, sectors. A recent example was a seminar on Grasslands Management, which was held in Saskatchewan in June 1991 in conjunction with the University of Regina. The seminar included a forum on conservation strategies for grasslands, and an extensive field-trip. Participants were awarded a certificate of grasslands management. Forthcoming certificate seminars have been organized with Wildlife Habitat Canada on Understanding, Planning, and Managing, Wetlands (November 1991) and Landscape Planning and Management (January 1992).

The public workshops focus on issues of interest or concern to the wider community and involve professionals and citizens. Recent workshops of this type examined the Canadian UNESCO Man and Biosphere Programme, planning for the Grand River in Ontario, and the conversion of rail-lines to hiking and biking trails. Upcoming workshops are to focus on Environmental Assessment and Heritage in Ontario, Heritage Practice in Canada, and Greenways for Ontario.

The Outreach Program is associated with a publication series that includes books, workshop proceedings, videos, papers, and technical reports, arising from the work of the Centre. Recent publications include Signposts to a Better Future: Environmental Assessment and Heritage in Canada, A Study of Ontario Volunteer Environmental Stewardship, Strengthening Biosphere Reserves in Canada, An Analysis of the Historical Interactions of Humans and Polar Bears in the Canadian Arctic 2000 BC to $A D$ 1935, and Marine, Lake and Coastal Heritage.

Through its activities, the Heritage Resources Centre strives to provide fora for information exchange, discussion, and learning, in a non-adversarial way. In this sense, it is becoming recognized as an important node for developing pluralistic and cooperative foci for environmental management and planning in Canada and internationally. Those interested in receiving a publications list, or in becoming better acquainted or involved with the work of the Centre, are encouraged to contact the Information Officer.

\section{J. Gordon Nelson, Chairman \& \\ RAFAL SERAFIn, Research Coordinator Heritage Resources Centre University of Waterloo \\ Waterloo \\ Ontario N2L $3 G 1$ \\ Canada.}

\section{The Banff Centre for Management's Recent or Impending Initiatives in Environmental Innovation}

\section{Proposed Institute of Environmental Innovation}

The Banff Centre for Management is actively exploring the possibility of establishing an Institute for Environmental Innovation within the Centre. Our goals in this endeavour are to raise the international profile and impact of our current programming in Resource and Environment Management, and to develop a new focus on applying the latest research on organizational and product innovation to the field of environmental management.

The Banff Centre has been offering programmes in resource and environment management since 1972, and is recognized as the leading institution in Canada in the area of management courses related to environmental issues. Current course offerings range from technical pro- 
grammes such as 'Industrial and Hazardous Waste Management' to skill-based programmes on 'Conflict Resolution' and 'Community Leadership' with due emphasis on environment-related applications. Courses in the area of 'Information Technology for Resource Management and Sustainable Development (Geographic Information Systems)' are now being expanded to meet the needs of a more broadly-based Canadian audience and of international audiences. A new programme in 'Business and the Environment' (the pilot course having been offered in the first quarter of 1991) is designed to provide senior executives with the tools to manage effectively changes within the context of increasing concern about the impact of corporate activity on the environment.

The Centre is also dedicated to bringing into the Canadian debate the experience of companies in Europe and in parts of Asia. To this end, it has developed a working relationship with the Institute for Business and the Environment at the European Business School in Wiesbaden, Germany. The Director of the Centre is also serving as the co-chairperson of the new Task Force on the Environment and Business which has been organized by the European Foundation for Management and Development in Brussels.

\section{Assistance to Managers Intended}

In addition to consolidating current programmes under the rubric of an Institute for Environmental Innovation, we expect to be seeking creative ways of assisting managers in a broad range of industries and businesses - to encourage and facilitate innovative research leading to the development of environmentally-sound products and processes. The focus of research to be carried out under the auspices of the Institute would be on continually developing and delivering new programmes and courses that reflect 'leading edge' knowledge, skills, and techniques, and on organizing international symposia and policy 'think-tanks'.

The theme of 'innovation' runs through many of the Centre for Management's new initiatives, and there are natural links between our plans relating to environmental innovation and our work in sensitive environmental fields. One aspect of that work will be an exploration of the impact of increasing concern about the environment on the way in which organizations structure themselves and carry out their activities. A project team, co-chaired by Robert A. Ferchat (recently retired President of Northern Telecom Canada and now Chairman of AECL) and Bryan Smith (President of Innovation Associates Canada), is actively exploring new course offerings which help people to develop a conceptual framework to understand the impact of change on their personal career and on their organizations, and to obtain practical skills to apply to planning, leading, and implementing, change.

\section{PAC Global Group and Festival*}

A main focus of the portion of the Organizational Innovation work that specifically looks at the theme of

\footnotetext{
* Too late to delete this section without costly disturbance of the issue's make-up, we learned that 'PAC has now dissolved' - which could be a pity, as seemingly useful ideas and initiatives were involved. - Ed.
}

environment as a catalyst for organizational change will be our involvement in a global network known as the PAC Global Group. This is a newly-formed association of individuals from North America, Europe, and some Asian and African countries, dedicated to seeking out examples of creative ideas and practices that are helping organizations to survive in a rapidly-changing world, and to communicating their findings in a practical and useful manner. PAC's creators include Tom Peters and members of the Tom Peters Group, and individuals from The Financial Times, INC magazine, the Economist Conference Unit, Frankfurter Allgemeine Zeitung, the 31 Venture Capital Group, and the Foresight Group of Sweden. The Banff Centre for Management has been working as a founding member of PAC, and agreement in principle has been reached with the Group to make Banff the centre for its operations in Canada.

Plans are afoot for a 'Global Festival of New Organizational Practice', organized by PAC, to be held in 1992 or 1993. The overall objective of the Festival is to challenge and to surprise - to encourage people to break old moulds and think in new ways about what organizations can be and what they can do for their members. A 'Mini-Festival' with two or three theme pavilions, to test the idea and start people thinking about what might be done, is tentatively planned for London, England. The Centre for Management has expressed interest in creating a pavilion with the theme 'Environmental Innovation' for this festival, and has initiated discussions with the Centre for the Arts on the possibility of collaborating on this venture.

\section{Environment Festival Possibility}

We have also approached the Centre for the Arts concerning the possibility of complementing our annual Mountain Film Festival with a more broadly-based Environment Festival. While this would build on our experience with the existing festival and would include an audio-visual component, it would also feature panel discussions, interactive learning media programmed to educate the general public about environmental issues, displays of new technology, music, drama, creative writing, and visual art exhibitions expressing a wide variety of environmental themes. It would not be a 'trade show', but rather a celebration of creative thought and work inspired by concern for the environment. Our approach would be to encourage Canadian and international organizations and individuals who are already working in this area to contribute displays, exhibits, materials, people, and ideas, to the festival.

More information about all of these activities was available in the Banff Centre for Management's Research and Development Proposal for the period 1 September 1990 to 31 August 1991, and in the short discussion papers on individual programmes that are being created as we begin to shape and implement these ideas.

Felicity Edwards, Program Manager Resource \& Environment Programs The Banff Centre for Management Box 1020

Banff

Alberta TOL OCO

Canada. 